REVISTA DE GESTÃO ESECRETARIADO

MANAGEMENT AND ADMINISTRATIVE

PROFESSIONAL REVIEW

ISSN: 2178-9010
Revista GeSec

São Paulo, SP, Brasil

v. 10 , n. 2 , p. $87-111$

mai/ago 2019

DOI: http://dx.doi.org/10.7769/gesec.v10i2.865

\title{
Licitações e compras públicas sustentáveis - evolução do conceito e aplicação no Estado de São Paulo
}

\section{Bids and sustainable public procurement - evolution of the concept and application in the State of São Paulo}

\author{
Jéssica Maria Cavalheiro Madeira ${ }^{1}$ \\ José Orcélio do Nascimento ${ }^{2}$ \\ Marcus Vinicius Moreira Zittei ${ }^{3}$ \\ Ricardo Rocha de Azevedo ${ }^{4}$
}

\section{Resumo}

A consciência da finitude dos recursos naturais impulsionou importantes mudanças de comportamentos das pessoas e das empresas com as questões ambientais e trouxe reflexos também para o setor público, que passou a entender a importância do desenvolvimento sustentável como um sistema, integrando ambiente, economia e sociedade. Neste contexto, existe um forte movimento para estimular as licitações e compras públicas sustentáveis. $\mathrm{O}$ objetivo desta pesquisa foi analisar se alguns órgãos públicos do Estado de São Paulo têm elaborado editais de compras públicas adequados às regras de sustentabilidade. A pesquisa pode ser definida como exploratória e descritiva, no tocante aos objetivos, pois realizada através da análise de dados divulgados por órgãos públicos, que proporcionaram a coleta de dados de base qualitativa, sendo que, com relação aos procedimentos adotados, trata-se de uma pesquisa documental. Para a análise foi considerada a aplicação do Decreto Estadual $\mathrm{n}^{\mathrm{o}}$ 59.038/2013, que instituiu o "Programa Paulista de Biocombustíveis". Apurou-se que os órgãos estaduais paulistas estão afinados com as determinações legais, porém não há, em grande parte dos editais, preocupação em mencionar expressamente a norma, gerando certa dúvida a respeito da real vinculação dos órgãos com a ideia inicial de utilizar as compras públicas como instrumento para fomentar a transformação de cultura dos mercados produtores e fornecedores.

Palavras-chaves: Compras públicas sustentáveis. Desenvolvimento sustentável. Sustentabilidade.

\footnotetext{
${ }^{1}$ Especialista em Gestão e Controladoria Pública, e Direito Penal e Processo Penal, Assessora Técnica da Assessoria Jurídica da Defensora Pública do Estado de São Paulo.

${ }^{2}$ Mestre em Ciências Contábeis, Professor da Fundação Escola de Comércio Álvares Penteado (FECAP).

${ }^{3}$ Doutor em Ciências Contábeis e Administração, Mestrado em Governança Corporativa do Centro Universitário Faculdades Metropolitanas Unidas (FMU) e do Mestrado em Administração da Universidade Ibirapuera (UNIB).

${ }^{4}$ Doutor em Controladoria e Contabilidade, Professor da Universidade Federal de Uberlândia (UFU).
} 


\begin{abstract}
The awareness of the finiteness of natural resources has led to important changes in the behavior of people and companies with environmental issues and has also brought about a reflection on the public sector, which has come to understand the importance of sustainable development as a system, integrating environment, economy and society. In this context, there is a strong movement to stimulate public procurement and sustainable procurement. The objective of this research was to analyze whether the public agencies of the State of São Paulo have prepared public procurement notices adequate to the sustainability rules set forth. The research can be defined as exploratory and descriptive, in relation to the objectives, as it was carried out through the analysis of data published by public agencies, which provided data collection on a qualitative basis, and in relation to the adopted procedures, a documentary research. For the analysis was considered the application of State Decree $n^{\circ}$ 59.038/2013, which instituted the "Programa Paulista de Biocombustíveis". It was found that the state organs of São Paulo are in tune with the legal determinations, but in the majority of the edicts there is no concern to expressly mention the norm, generating some doubt about the real linking of the organs with the initial idea of using the purchases as a tool to foster the transformation of the culture of producer and supplier markets.
\end{abstract}

Keywords: Sustainable public procurement. Sustainability. Sustainable Development.

\title{
Introdução
}

No Brasil, a preocupação com as questões ambientais está inserida no ordenamento jurídico em diversas normas. Na Constituição Federal é possível verificar princípios e regras em diversos dispositivos, inclusive no capítulo dedicado à ordem econômica (art. 170, inciso VI), demonstrando que mesmo nas relações econômicas não se pode olvidar da defesa do meio ambiente.

Por isso, cada vez mais, os órgãos públicos buscam aplicar os conceitos de sustentabilidade, tanto nas suas estruturas internas, como nas contratações que realizam. Já existem grupos bastante engajados dentro de vários órgãos públicos incentivando a prática das licitações sustentáveis, que apesar de ser um assunto pouco explorado nas doutrinas jurídicas e administrativas, na prática estão ganhando muita força, principalmente a partir da compreensão de que as compras públicas sustentáveis podem acarretar ganho de escala e reduzir o valor dos produtos (Silva\&Barki, 2012).

A aplicação de algumas mudanças na forma de aquisição pelo setor público possibilita que os "processos licitatórios sustentáveis garantam o meio ambiente ecologicamente 
equilibrado, de modo a não gerar impactos ambientais com externalidades negativas" (Costa, Diniz, Cunha\& Pires, 2016).

Outro fator muito importante das contratações e aquisições públicas, como definido por Moreira (2011), que entende importante que a Administração aplique as exigências socioambientais mínimas nas suas contratações, mas antes disso, deve ter clareza da real necessidade daquela contratação, também aplicando os conceitos de consumo sustentável.

No Estado de São Paulo muitos decretos e leis foram publicados visando garantir compras sustentáveis, inclusive, a partir do Decreto Estadual $n^{\circ} 50.170$, de 04 de novembro de 2005, foi instituído o "Selo Socioambiental" no âmbito da Administração Pública Estadual e para disponibilizar aos órgãos públicos paulistas mais uma ferramenta para aumentar a conscientização no que diz respeito às compras públicas. Tal ação evoluiu para a criação das regras previstas no Decreto Estadual $\mathrm{n}^{\mathrm{o}}$ 53.336, de 20 de agosto de 2008, que definiu expressamente o "Programa Estadual de Contratações Públicas Sustentáveis".

A presente pesquisa tem como objetivo analisar se alguns órgãos públicos do Estado de São Paulo têm elaborado editais de compras públicas adequados às regras de sustentabilidade.

A partir disso, o objetivo específico foi utilizar uma determinada norma, no caso o Decreto Estadual no 59.038/2013, que instituiu o "Programa Paulista de Biocombustíveis", para verificar se a existência de normas e disponibilização de ferramentas estimulou a implantação das medidas socioambientais nas compras públicas. Destarte, apurar se houve a divulgação da norma para influenciar a conscientização e mudança de cultura dos mercados produtores e fornecedores.

Tais informações foram coletadas através de análise de dados disponibilizados em sítios eletrônicos pelos órgãos públicos, bem como feita pesquisa na doutrina especializada, em artigos científicos e em publicações nacionais e internacionais referentes ao tema. Foram analisados editais de pregões eletrônicos disponibilizados pelos órgãos públicos, nos anos de 2014 a 2016, referentes a contratações de serviços de locação ou aquisição de veículos ou de abastecimento da frota

Revista Gestão e Secretariado (GeSec), São Paulo, SP, v. 10, n. 2, mai/ago, 2019, p. 87-111. 
Considerando o papel de coerção desses órgãos perante dos demais órgãos públicos do Estado, a utilização das regras sustentáveis por eles pode criar incentivos para que os demais utilizem. Além disso, em caso de não conformidade, esses órgãos perderiam legitimidade de ação, gerando incentivos negativos para os demais.

\section{REFERENCIAL TEÓRICO}

\subsection{Sustentabilidade}

O conceito de sustentabilidade abrange a análise dos impactos social, econômico e ambiental, conforme definido pela primeira vez na "Carta da Terra", documento produzido na $\mathrm{RIO} / 92$.

Além dessas três dimensões da sustentabilidade, Freitas (2016) traz o conceito multidimensional, com a inclusão de outras duas dimensões: a jurídico-política, considerando a tutela jurídica do direito ao futuro independentemente de regulamentação, e a ética, considerando que todos os seres vivos, humanos ou não, possuem uma ligação intersubjetiva e natural.

$\mathrm{Na}$ área pública, o Administrador deve basear suas decisões considerando a sustentabilidade em sua forma multidimensional ou pluridimensional, respeitando o direito das gerações presente e futuras, mas, além disso, como já defendia Bosselman (2015) como citado em Moreira (2017), ao definir uma perspectiva lógica de justiça, é importante se preocupar com as formas de vida não humanas e na inter-relação das pessoas com o meio ambiente e os animais.

SarleteFensterseifer (2013) defendem o conceito da dimensão ecológica da dignidade da pessoa humana, que seria uma forma de ampliação do conceito da proteção da dignidade humana, para incluir a solidariedade e o respeito dos seres humanos com a natureza para garantir a sobrevivência de todos, sendo o bem-estar ambiental fundamental para uma vida digna, saudável e segura.

Revista Gestão e Secretariado (GeSec), São Paulo, SP, v. 10, n. 2, mai/ago, 2019, p. 87-111. 
A sustentabilidade é um valor supremo na Constituição Brasileira e uma diretriz vinculante, que exige mudanças de hábitos e comportamentos, para se atingir o equilíbrio da vida. Tanto que ele elenca quatro vícios principais que geram políticas insustentáveis: patrimonialismo (uso do poder como máquina privada sem preocupação socioambiental); tráfico de influências (uso da máquina pública para se obter vantagens indevidas); omissivismo (falta de atuação diante de problemas conhecidos); mercenarismo (prevalece o interesse econômico) (Freitas, 2016).

A organização não-governamental World WildlifeFund (WWF), criada em 1961, desenvolveu o conceito da "Pegada Ecológica Global", que é "uma metodologia de contabilidade ambiental que avalia a pressão do consumo das populações humanas sobre os recursos naturais", e que "permite comparar diferentes padrões de consumo e verificar se estão dentro da capacidade ecológica do planeta". Demonstram que nos dias atuais consumimos $50 \%$ a mais do que o que temos disponível em recursos naturais e as "projeções para o ano de 2050 apontam que, se continuarmos com este padrão, necessitaremos de mais de dois planetas para mantermos nosso consumo" (WWF, 2017).

Em 1990 foi criado o ICLEI -InternationalCouncil for Local Environmental Initiatives -Governos Locais pela Sustentabilidade, que engloba cerca de 1.500 governos de estados e cidades de diversos portes, em mais de 100 países, entre cidades e associações de governos locais no mundo, que auxiliam a promoção do desenvolvimento sustentável. Em 2006 foi montado o escritório para o Brasil, na cidade de São Paulo (ICLEI, 2015).

Os participantes do ICLEI têm plena consciência da importância da aplicação da sustentabilidade nas compras públicas, considerando o grande poder de compra de governos locais, por isso definiram objetivos como: integrar critérios de sustentabilidade em todas as fases do processo de compras públicas para reduzir o impacto da produção e do consumo sobre a saúde humana e o meio ambiente; garantir economia para a administração e criar novos mercados para produtos sustentáveis (ICLEI, 2015).

Revista Gestão e Secretariado (GeSec), São Paulo, SP, v. 10, n. 2, mai/ago, 2019, p. 87-111. 


\subsection{Licitações e compras públicas sustentáveis}

Segundo Coelho (2014) é uma tendência mundial, já observada em países como Alemanha, Estados Unidos, Inglaterra, Austrália e Suécia, além de diversos outros, que o futuro das licitações e compras públicas seja sustentável, inclusive define o termo como "ecolicitações".

Moreira (2014) ao analisar a "Força-Tarefa de Marrakesh sobre compras públicas sustentáveis" (Marrakesh Task Force onSustainnablePublicProcurement) destacou a definição trazida por esse grupo, formado por grandes especialistas na área, como um processo pelo qual as organizações atendem suas necessidades de contratações e aquisições "de modo a alcançar um valor baseado em um conceito completo de vida, ao gerar benefícios não só para a organização, mas também para a sociedade e a economia", minimizando os danos ao meio ambiente. Além disso, tal conceito ressalta a importância que as despesas governamentais têm na economia dos países, por isso essas contratações têm grandes influências nas mudanças dos padrões de produção e consumo.

Como defende Coelho (2014), o poder público tem o dever de "liderar o aguçamento da consciência ambiental, por meio de suas vultosas aquisições, capazes de incentivar indústria, comércio e consumidores a utilizar bens e serviços ambientalmente corretos".

Conforme Freitas (2016), as contratações públicas devem analisar e ponderar sobre os custos e benefícios, principalmente os indiretos, pois "o que se afigura o custo menor, isoladamente considerado, pode representar o custo proibitivo, quando os efeitos colaterais e involuntários (externalidades) forem incorporados à apreciação". As licitações e compras sustentáveis devem trabalhar com modelos paramétricos de estimativas razoáveis dos custos diretos e indiretos.

O ciclo de vida mais longo dos produtos sustentáveis é um dos grandes atrativos para que as pessoas optem pela mudança no padrão de consumo, pois além de se gastar menos a longo prazo, gera menor quantidade de resíduos para o meio ambiente, ou consomem menos energia, diminuindo, assim, o impacto ambiental (Torres, 2012).

Revista Gestão e Secretariado (GeSec), São Paulo, SP, v. 10, n. 2, mai/ago, 2019, p. 87-111. 
A evolução legislativa brasileira com relação às licitações e compras públicas sustentáveis acabou por transformar a compreensão da avaliação da vantajosidade, que passou a ser analisada não só pela proposta mais vantajosa economicamente, mas também considerando os aspectos de promoção do desenvolvimento sustentável (Moreira, 2017).

Outro ponto importante dessas contratações é a influência que exercem sobre a produção, que passa a se preocupar mais com as matérias-primas e os processos produtivos, bem como com o ciclo de vida de produtos e serviços (Freitas, 2016).

Arrowsmith, Treumer, Fejo e Jiang (2011) definem alguns objetivos para a implementação das contratações públicas The objectives o fpublic procurement systems and regulatory provisions", sendo que o objetivo 6 define os critérios de sustentabilidade, como é possível ver a seguir:

Objective 1: value for money (efficiency) in the acquisition of required goods, works or services;

Objective 2: integrity - avoiding corruption and conflicts of interest;

Objective 3: accountability;

Objective 4: equal opportunities and equal treatment for providers;

Objective 5: fair treatment of suppliers;

Objective 6: efficient implementation of industrial, social and environmental policies in procurement;

Objective 7: opening up public markets to international trade;

Objective 8: efficiency in the procurement process.

Freitas (2016) defende que as regras sustentáveis nas licitações e contratações públicas são obrigatórias, considerando o mandamento constitucional, as quais podem ser definidas da seguinte forma:"São aquelas que, com isonomia, visam a seleção de proposta mais vantajosa para a Administração Pública, ponderados com a máxima objetividade possível, os custos e benefícios, diretos ou indiretos, sociais, econômicos e ambientais".

Meneguzzi (2015) menciona o parecer emitido pela Procuradora Chefe da Secretaria do Meio Ambiente do Estado de São Paulo (Parecer CJ $\backslash S M A n^{0}$ 683/2006), que defende que a inserção de critérios socioambientais na descrição do objeto em uma licitação não é forma de 
discriminação, mas sim atendimento à determinação legal do artigo 40, inciso I, da Lei Federal no $8.666 / 1993$.

Como define Barcessat (2015) quando o Estado utiliza o seu poder de compra como forma de regulação social, como nas licitações sustentáveis, respeitando as leis e princípios constitucionais, está longe de ferir o princípio da igualdade, nem pouco prejudica a competitividade, mas na verdade está utilizando seu dever de ordenação da atividade econômica, fomentando práticas voltadas ao desenvolvimento socioambiental.

\subsubsection{Princípios Constitucionais e Legislação Federal Brasileira}

Nota-se que o arcabouço normativo brasileiro demonstra preocupação e cria obrigações com relação à sustentabilidade, inclusive com princípios e regras previstos na Constituição Federal Brasileira de 1988. Já no artigo $1^{\circ}$, inciso III, define-se como um dos fundamentos do Estado a "dignidade da pessoa humana", que como apresentado acima, na obra de Sarlet e Fensterseifer (2013), possui sua dimensão ecológica.

$\mathrm{Na}$ Constituição Federal Brasileira encontram-se vários princípios relacionados à sustentabilidade: o princípio da eficiência ( $\mathrm{CF}$, art. 37) determina a utilização de "meios apropriados e pertinentes" na execução de tarefas pela Administração Pública; o princípio da eficácia ( $\mathrm{CF}$, art. 74) prevê a obrigação de sistemas de controle para fiscalização das metas definidas, e o princípio da economicidade (CF, art. 70) é observado a partir do momento em que se considera os ganhos a longo prazo.

No artigo 170, inciso VI, da Constituição Federal, que trata da ordem econômica, está prevista a defesa do meio ambiente, inclusive mediante tratamento diferenciado, conforme o impacto ambiental dos produtos e serviços e de seus processos de elaboração e prestação. Esse dispositivo foi acrescentado pela Emenda Constitucional n ${ }^{\circ}$ 42/2003.

Já o artigo 225 da Constituição Federal define o dever de todos, Poder Público e Sociedade, na proteção ao meio ambiente:

Revista Gestão e Secretariado (GeSec), São Paulo, SP, v. 10, n. 2, mai/ago, 2019, p. 87-111. 
Art. 225. Todos têm direito ao meio ambiente ecologicamente equilibrado, bem de uso comum do povo e essencial à sadia qualidade de vida, impondo-se ao Poder Público e à coletividade o dever de defendê-lo e preservá-lo para as presentes e futuras gerações.

Freitas (2016) entende que o artigo 225 traz um complemento indissociável ao preâmbulo da Constituição Federal, que traz o termo desenvolvimento, que deve ser entendido como desenvolvimento sustentável.Além disso, é possível extrair diversos princípios.

No princípio da obrigatoriedade da intervenção estatal, encontram-se dois princípios bastante relevantes com relação aos estudos ambientais e na formulação de políticas públicas, são eles: da precaução e da prevenção, que "constituem-se em mecanismos para a gestão antecipatória, inibitória e cautelar de riscos ambientais” (Bertogna, 2015).

O princípio da solidariedade intergeracional ou equidade assegura direitos às gerações futuras a utilizarem os recursos naturais do planeta, criando, portanto, restrições de uso aos ocupantes atuais da Terra e condiciona a criação de políticas públicas que considerem a sustentabilidade a longo prazo (Bertogna, 2015).

Uma das primeiras leis que refletiram uma preocupação mais relacionada às questões ambientais no Brasil foi a Lei Federal $n^{0}$ 6.938/1981, que instituiu a Política Nacional do Meio Ambiente. Publicada na mesma época em que se percebe no mundo uma mudança de comportamento com as questões ambientais.

No âmbito das licitações e contratações públicas, com a publicação da Lei Federal $\mathrm{n}^{\circ}$ 8.666/1993, houve uma regra geral com um viés ambiental, pois o artigo 12, inciso VIII, da Lei previu a necessidade de observação do impacto ambiental das compras e contratações públicas. Tal previsão foi colocada de forma tímida e trouxe pouca efetividade na prática.

Posteriormente, o artigo $3^{\circ}$, da Lei Federal $n^{\circ}$ 8.666/1993, foi alterado pela Lei Federal $\mathrm{n}^{\mathrm{o}}$ 12.349/2010, para demonstrar uma maior preocupação com o aspecto da sustentabilidade nas regras de licitações. Apesar de ainda ser de forma muito insipiente, foi mais um passo para o balizamento das ações dentro dos órgãos públicos:

Revista Gestão e Secretariado (GeSec), São Paulo, SP, v. 10, n. 2, mai/ago, 2019, p. 87-111. 
Art. $3^{\circ}$ - A licitação destina-se a garantir o princípio constitucional da isonomia, a seleção da proposta mais vantajosa para a administração e a promoção do desenvolvimento nacional sustentável e será processada e julgada em estrita conformidade com os princípios básicos da legalidade, da impessoalidade, da moralidade, da igualdade, da publicidade, da probidade administrativa, da vinculação ao instrumento convocatório, do julgamento objetivo e dos que lhes são correlatos. (grifonosso)

Tal alteração legislativa foi criticada por alguns estudiosos da área pela maneira que foi introduzida, já que foi colocada como finalidade da licitação e não da contratação pública. A licitação é uma das formas de contratação pública. Já o conceito de contratação pública é muito mais abrangente e pode servir como ferramenta de mudança de comportamentos na economia (Freitas, 2014).

A lei geral de licitações trazia mais preocupação com as questões da isonomia e da proposta mais vantajosa, mas já era possível observar a exigência de critérios de sustentabilidade no artigo $5^{\circ}$, inciso XIII, alínea $b$, e no artigo $6^{\circ}$, inciso XII, ambos da Lei Federal $n^{\circ}$ 12.187/2009, que definiu a Política Nacional de Mudanças Climáticas, bem como no artigo $6^{\circ}$, inciso XI, da Lei Federal $n^{\circ} 12.305 / 2010$, que criou a Política Nacional de Resíduos Sólidos (Moreira, 2017).

O Decreto Federal $n^{0} 7.746 / 2012$ regulamentou o art. $3^{\circ}$ da Lei $n^{\circ} 8.666 / 1993$, para estabelecer critérios, práticas e diretrizes para a promoção do desenvolvimento nacional sustentável nas contratações realizadas pela administração pública federal, e institui a “Comissão Interministerial de Sustentabilidade na Administração Pública - CISAP”.

Posteriormente, a Lei Federal no 12.462/2011, estabeleceu o Regime Diferenciado de Contratações Públicas, que trouxe de forma expressa o princípio do desenvolvimento nacional sustentável de forma mais completa, referindo-se às licitações e aos contratos:

Art. $3^{\circ}$ - As licitações e contratações realizadas em conformidade com o RDC deverão observar os princípios da legalidade, da impessoalidade, da moralidade, da igualdade, da publicidade, da eficiência, da probidade administrativa, da economicidade, do desenvolvimento nacional sustentável, da vinculação ao instrumento convocatório e do julgamento objetivo (grifo nosso)

Embora existam várias normas, ainda é necessário buscar alternativas de atuações dotadas de maior efetividade e com ressonância social, que possibilitem as pessoas analisarem 
as externalidades negativas e os custos ambientais de suas ações, como é possível observar na redação do artigo $4^{\circ}$, inciso III, da Lei Federal n ${ }^{\circ}$ 12.462/2011 (Freitas, 2016):

III - busca da maior vantagem para a administração pública, considerando custos e benefícios, diretos e indiretos, de natureza econômica, social ou ambiental, inclusive os relativos à manutenção, ao desfazimento de bens e resíduos, ao índice de depreciação econômica e a outros fatores de igual relevância (grifo nosso).

As normas constitucionais e as leis acima citadas balizam as atividades públicas sustentáveis no país, principalmente a atuação dos órgãos federais, criando também estímulos para a criação das regras regionais e locais.

\subsubsection{Algumas experiências internacionais}

$\mathrm{Na}$ Europa as ações do ICLEI já atingiram números expressivos, destacando-se a implantação da "Iniciativa Européia de Compras Verdes", em 2002, que apresentou como resultado a grande adesão de governos locais na realização de compras sustentáveis, por exemplo: Suécia (50\%), Reino Unido (23\%), Espanha (23\%). Além disso, diversas outras ações nesse mesmo sentido refletem comprometimento dos governos locais (ICLEI, 2015).

Inclusive a Comissão Europeia, em parceria com ao ICLEI, desenvolveu um manual de compras ecológicas (Comprar ecológico! Manual de Contratos Públicos Ecológicos), no qual define todas as regras para facilitar a implantação e elaboração de contratos públicos ecológicos. Neste manual "estão disponíveis técnicas, como o cálculo dos custos do ciclo de vida, a especificação de processos de produção sustentáveis e a utilização de critérios de adjudicação ambientais, para ajudar as entidades adjudicantes a identificar propostas preferíveis do ponto de vista ambiental" (Comissão Europeia, 2016).

Na Espanha pode se destacar o Guía de Contratación Pública Sostenible, que já no início indicou que 16\% do Produto Interno Bruto espanhol foi proveniente das contratações públicas, por isso exerce grande influência nos setores social, econômico e ambiental. Assim, há a junção da preocupação da compra verde (atendimento a pré-requisitos ambientais), compra ética (respeito às garantias trabalhistas) e compra social (qualidade do emprego, respeito às diferenças, entre outros) (Freitas, 2014).

Revista Gestão e Secretariado (GeSec), São Paulo, SP, v. 10, n. 2, mai/ago, 2019, p. 87-111. 
A União Europeia tem regras próprias que são aplicadas a todos os países que a compõe, mas a legislação da Espanha é bastante avançada com relação às licitações sustentáveis. Inclusive existe um ponto interessante da diferença de inspiração entre as legislações brasileira e espanhola, que enquanto no Brasil existem regras de fomento para a contratação de micro e pequenas empresas, na Espanha a preocupação não é com o tamanho da empresa, mas sim com que tipo de trabalhador ela contrata, havendo incentivos para empresas que se preocupam em reinserir pessoas desempregadas há muito tempo, ou que contratam pessoas com deficiências (Freitas, 2014).

\subsubsection{Algumas experiências nacionais}

No Brasil existem inúmeras ações na área socioambiental aplicada às licitações e compras públicas.

Em 1999 foi publicadaa “Agenda Ambiental da Administração Pública - A3P”, pelo Ministério do Meio Ambiente, que foi criada oficialmente em 2001, e se tornou um dos principais instrumentos que definem a adesão de um órgão público aos critérios socioambientais, inclusive recebeu um prêmio da UNESCO no ano de 2002, como "O melhor dos exemplos" na categoria Meio Ambiente. Este programa integra o Departamento de Produção e Consumo Sustentáveis (DPCS), da Secretaria de Articulação Institucional e Cidadania Ambiental (SAIC) do Ministério do Meio Ambiente.

Os responsáveis por essa agenda identificam alguns desafios para implementação das regras socioambientais como: a necessidade de indicadores e aparato técnico-científico que respalde possíveis ações; necessidade de investimento em educação como base para mudanças; a cultura institucional; a corrupção no Poder Público como justificativa; não criação de uma área específica no órgão que cuide somente da A3P; sobreposição de tarefas. Os órgãos que conseguiram superar essas barreiras e aderiram à A3P estão apresentando resultados muito expressivos na área socioambiental (MMA, 2017).

Dentre os órgãos federais temos alguns bons exemplos de implantação desse programa de sustentabilidade muito bem-sucedidos.

Revista Gestão e Secretariado (GeSec), São Paulo, SP, v. 10, n. 2, mai/ago, 2019, p. 87-111. 
A Advocacia Geral da União (AGU), em setembro de 2008, aderiu ao Programa A3P, do Ministério do Meio Ambiente. Desde então, além de mudanças práticas e estruturais no funcionamento dos seus órgãos, passou a produzir documentos muito importantes como o "Guia Nacional de Licitações Sustentáveis" e o "Guia Prático de Licitações Sustentáveis da CJU/SP”, que estão auxiliando diversos órgãos a implementar os conceitos de licitações sustentáveis, principalmente na esfera federal (AGU, 2016).

Outro expoente importante é o Tribunal de Contas da União, que no dia 24 de maio de 2017 emitiu o Acórdão no 1056/2017 (TCU, 2017), após votação do Plenário, que refletiu amplamente nos atuais posicionamentos da Corte de Contas Federal no tocante à sustentabilidade, tanto em âmbito interno, como aplicada às fiscalizações dos demais órgãos federais.

Tal acórdão foi proferido após a auditoria operacional nas ações adotadas pela Administração Pública Federal nas áreas de redução de consumo de papel, energia elétrica e de água, a fim de avaliar as medidas efetivamente adotadas após as recomendações do Acórdão nº 1.752/2011 - TCU - Plenário (TCU, 2011).

Os principais problemas apontados na auditoria foram: grau insuficiente de gestão e implementação de ações de promoção da sustentabilidade; deficiências de atuação no nível central de governo; baixa evolução na adoção de critérios e práticas sustentáveis nas contratações; pouca implementação de ações que visem à utilização de edifícios públicos mais eficientes e sustentáveis; deficiências nas iniciativas relacionadas à gestão de resíduos e realização de coleta seletiva solidária.

Influenciados pelas atividades do Ministério do Meio Ambiente e do Tribunal de Contas da União diversos órgãos federais estão aderindo às práticas socioambientais, tanto em suas estruturas, como nas compras e licitações realizadas. Já nas esferas estadual e municipal a adesão é menor, mas já existem importantes ações sendo desenvolvidas.

Revista Gestão e Secretariado (GeSec), São Paulo, SP, v. 10, n. 2, mai/ago, 2019, p. 87-111. 


\subsubsection{Licitações e compras públicas no Estado de São Paulo}

Os órgãos públicos estaduais de São Paulo realizam algumas contratações eletronicamente dentro de um sistema, criado pelo Decreto Estadual $n^{0}$ 45.695/2001, denominado Bolsa Eletrônica de Compras do Governo do Estado de São Paulo - Sistema BEC/SP (BEC).Esse sistemafoi evoluindo com o passar do tempo e atualmente pode ser utilizado para contratações através de dispensas de licitação, convites e pregões eletrônicos, e através desse sistema os órgãos públicos estaduais paulistas conseguem não só realizar suas atividades, como buscar comparativos para formações de preços e até modelos de editais.

Para facilitar a aquisição ou contratação pelos órgãos públicos do Estado de São Paulo de produtos e serviços que atendam critérios socioambientais foi criado o "Selo Socioambiental", através do Decreto Estadual no 50.170/2005. Para receber o selo, o produto ou serviço deve atender pelo menos um dos critérios elencados do artigo $2^{\circ}$ do Decreto:

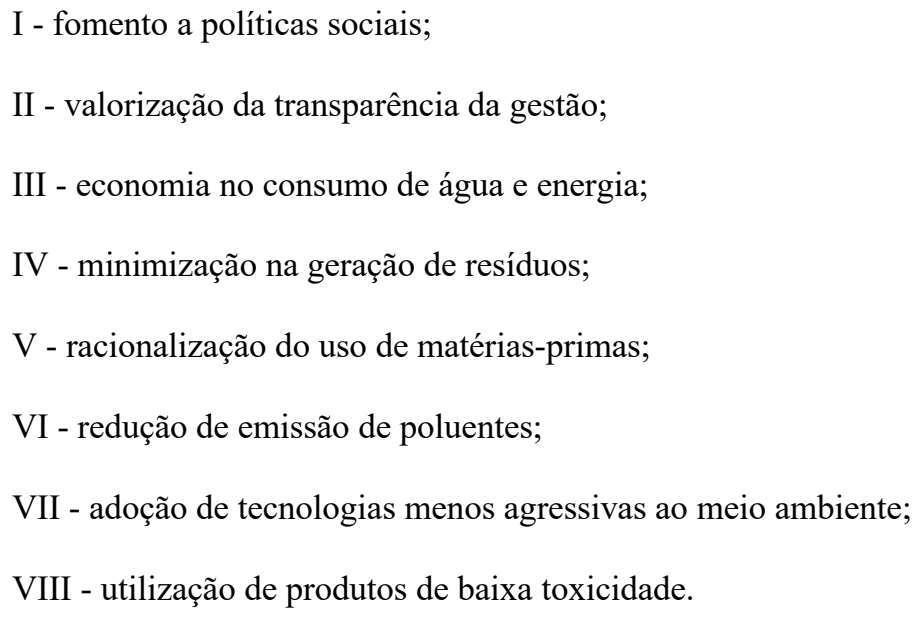

Os produtos e serviços que ganham esse selo passam a integrar o "Catálogo Socioambiental”, disponível no portal eletrônico do Sistema BEC/SP (BEC), sendo que a análise e validação do produto ou serviço são feitas pela Secretaria do Meio Ambiente do Estado de São Paulo.

O "Catálogo Socioambiental” é gerido pela Secretaria de Gestão Pública, a qual cabe a coordenação do Programa Estadual de Contratações Públicas Sustentáveis, e está separado do catálogo dos demais bens e serviços, sendo uma importante ferramenta para facilitar a implementação de critérios socioambientais nas licitações e compras públicas.

Revista Gestão e Secretariado (GeSec), São Paulo, SP, v. 10, n. 2, mai/ago, 2019, p. 87-111. 
O Programa Estadual de Contratações Públicas Sustentáveis - CPS foi criado pelo Decreto Estadual $n^{0} 53.336 / 2008$ para garantir a aplicação da política da sustentabilidade nas operações realizadas por órgãos públicos do Estado de São Paulo e incentivar a escolha de produtos e serviços com o "Selo Socioambiental".

Apesar de diversos órgãos públicos paulistas possuírem autonomia administrativa e poderem criar seus próprios sistemas de contratações, na prática a adesão ao Sistema BEC/SP pode ser um facilitador para ampliação das práticas socioambientais.

Além disso, é possível notar outras atitudes que buscam melhorar os aspectos socioambientais dentro dos órgãos como a proposta do Tribunal de Justiça do Estado de São Paulo, que implantou há cerca de três anos uma competição sustentável entre as unidades do Tribunal, chamada "TJ Sustentável", para "estimular o consumo consciente de recursos naturais e bens públicos entre servidores, magistrados e demais frequentadores do Judiciário".

$\mathrm{Na}$ Portaria $\mathrm{TJ}_{\mathrm{n}}^{0}$ 9.396/2017 foram definidas as metas dos prédios para este ano, quais sejam: economizar água, energia e papel sulfite, bem como implantar a coleta seletiva. As três primeiras colocadas recebem o "Selo Verde 2017", além de diversos prêmios, que foram doados por entidades parceiras (Tribunal de Justiça).

\section{METODOLOGIA}

A presente pesquisa se baseou na análise de editais publicados por alguns órgãos públicos do Estado de São Paulo, sendo eles o Tribunal de Justiça, o Ministério Público, a Defensoria Pública, o Tribunal de Contas e a Procuradoria Geral do Estado, para avaliar a aplicação de conceitos de sustentabilidade das licitações e compras públicas.

Quanto aos objetivos a pesquisa pode ser definida como exploratória e descritiva, visto que foi realizada através da análise de dados divulgados por órgãos públicos, em seus sítios eletrônicos oficiais, referentes à área de sustentabilidade e de licitações ou compras públicas sustentáveis.

Revista Gestão e Secretariado (GeSec), São Paulo, SP, v. 10, n. 2, mai/ago, 2019, p. 87-111. 
Segundo Gil (2010), a pesquisa exploratória objetiva criar maior proximidade com o problema, envolvendo o levantamento bibliográfico, entrevistas e análises de exemplos, que estimulem a compreensão do assunto, as pesquisas descritivas têm, primordialmente, a intenção de descrever as características de determinado fenômeno ou, ainda, estabelecer relações entre variáveis. Acrescenta-se a tal definição à colocação de Sampieri, Colladoe Lucio (2013), que definem que os estudos descritivos servem para analisar como é e como se manifestam um fenômeno e seus componentes.

A natureza da pesquisa tem base qualitativa como as buscas de editais de pregões eletrônicos em sítios eletrônicos de órgãos governamentais como Defensoria Pública do Estado de São Paulo, Ministério Público do Estado de São Paulo, Tribunal de Contas do Estado de São Paulo, Tribunal de Justiça do Estado de São Paulo, Procuradoria Geral do Estado de São Paulo.

Martins e Theóphilo (2009) entendem que a pesquisa qualitativa tem como preocupação central descrições, compreensões e interpretações dos fatos ao invés de medições. A pesquisa qualitativa é usada quando o assunto não possui muitas informações, ou quando se pretende conhecer o funcionamento de uma estrutura, assim, não há o objetivo de comprovar evidências, apenas são expostas as reflexões sobre o tema que surgirão ou se consolidarão durante a coleta e análise de dados. Corroborando tal ideia, Sampieri, Collado e Lucio (2013) definem como um método que utiliza coleta de dados sem medição numérica para descobrir ou aperfeiçoar questões de pesquisa e pode ou não provar hipóteses em seus processos de interpretação.

Com relação aos procedimentos adotados trata-se de uma pesquisa documental e a coleta de dados foi realizada através da busca de editais de pregões eletrônicosem sítios eletrônicos de alguns órgãos públicos do Estado de São Paulo, com preferência para aqueles que têm atuação no sistema de justiça paulista, bem como o Tribunal de Contas que realiza o controle externo desses órgãos.

Os documentos analisados são editais de pregões eletrônicos disponibilizados por esses órgãos, nos anos de 2014, 2015 e 2016, referentes a contratações de serviços de locação ou aquisição de veículos ou de abastecimento da frota, para verificar se os órgãos atendem ao 
disposto no Decreto Estadual $\mathrm{n}^{\mathrm{o}}$ 59.038/2013, que instituiu o Programa Paulista de Biocombustíveis, determinando a aquisição e locação de veículos com motor flex para a frota do Estado.

A análise documental é apontada por Martins e Theóphilo (2009) como uma das técnicas mais usadas nas pesquisas qualitativas. No entendimento de Gil (2010) a pesquisa documental assemelha-se à pesquisa bibliográfica, diferenciando-se pela natureza das fontes: enquanto na bibliográfica são utilizados trabalhos já desenvolvidos por outros autores a respeito de certo tema, entendam-se, fontes secundárias, na documental são utilizados materiais de fontes mais diversas, tanto aqueles que já receberam algum tipo de análise, quanto àqueles que não receberam nenhum tipo de tratamento analítico.

A partir das informações coletadas foi possível analisar a forma de atuação de alguns órgãos públicos selecionados, verificando se estão atendendo a pelo menos uma das normas existentes para realização de compras e licitações sustentáveis.

\section{ANÁLISE E DISCUSSÃO DOS RESULTADOS}

Foram verificados editais de licitações, da espécie pregão, sendo considerados os pregões eletrônicos ou presenciais, referentes a contratações de serviços de locação ou de aquisição de veículos ou de serviços de abastecimento da frota, para verificar se os órgãos atendem ao disposto no Decreto Estadual no 59.038/2013, que instituiu o "Programa Paulista de Biocombustíveis".

A política pública implantada com este decreto é um exemplo de que a avaliação da vantajosidade deve não só considerar aspectos econômicos, mas também a promoção do desenvolvimento sustentável (Moreira, 2017).

O DecretoEstadual n ${ }^{0} 59.038 / 2013$ determina que a aquisição ou a locação de veículos pelos órgãos públicos paulistas devem observar a preferência por aqueles que possuem motor flex, permitindo o abastecimento por etanol hidratado ou gasolina (artigo $2^{\circ}$ ), bem como indica que nesses casos o abastecimento deve ser feito, preferencialmente, por etanol 
hidratado (artigo $3^{\circ}$ ). Ambas obrigações permitem a flexibilização da escolha, desde que devidamente justificada pelo administrador.

No caso de aquisição ou locação, é possível a escolha de veículos com motor abastecidos exclusivamente por gasolina ou diesel, desde que não seja fabricado o modelo necessário no tipo flex, ou os modelos flex não atendam à necessidade da Administração (art. $2^{\circ}$, parágrafo único). Já na escolha do combustível dos veículos com motor flex, só será possível o abastecimento com gasolina, se devidamente justificada a inviabilidade técnica ou econômica (art. $3^{\circ}$, parágrafo único).

A obrigatoriedade de abastecimento de carros utilizados pelos órgãos públicos no Estado de São Paulo, apenas com álcool (ou etanol), já existe desde o Decreto Estadual $n^{o}$ 42.836/1998, que foi alterado pelo Decreto $n^{\circ} 48.092 / 2003$ e revogado pelo Decreto $n^{o}$ $59.038 / 2013$.

No decreto de 1998 já havia a imposição de aquisição e a locação de veículos movidos à álcool para a frota da Administração Pública Direta e Indireta, porém, o decreto de 2013 revogou seu antecessor, trazendo uma série de outras obrigações, bem como atualizando a obrigatoriedade para o motor flex, que não existia anteriormente.

Para coleta de dados, a análise considerou os editais publicados no período de 2014 a 2016, tendo em vista que o decreto foi publicado em 2013, além disso, a pesquisa foi realizada naqueles editais que estão disponíveis nos sítios eletrônicos dos órgãos supracitados. Somente com relação à Defensoria Pública que os editais não estavam disponíveis, apenas constava a informação da realização das licitações, mas o Departamento de Licitações da Defensoria prontamente atendeu à solicitação de envio dos arquivos.

Tabela 1 Licitações

Pregões realizados entre 2014 e 2016

PREVISÃO SUSTENTÁVEL DO EDITAL - uso de combustível etanol

\begin{tabular}{l|c|c|c|c|c|c}
\hline Órgão & Modalidade & $\begin{array}{c}\text { Sessão } \\
\text { pública }\end{array}$ & \multirow{2}{*}{ Objeto } & \multicolumn{3}{|c}{ Menção ao decreto estadual 59.038/13 } \\
\cline { 4 - 6 } & & & Sim & $\begin{array}{c}\text { Não, mas possui requisitos } \\
\text { sustentáveis }\end{array}$ & $\begin{array}{c}\text { Não e não } \\
\text { atende }\end{array}$ \\
\hline
\end{tabular}

Revista Gestão e Secretariado (GeSec), São Paulo, SP, v. 10, n. 2, mai/ago, 2019, p. 87-111. 

aplicação no Estado de São Paulo

\begin{tabular}{|c|c|c|c|c|c|c|}
\hline PGE/SP & $\begin{array}{l}\text { Pregão } \\
\text { eletrônico } n^{\circ} \\
028 / 2014\end{array}$ & $29 / 12 / 2014$ & $\begin{array}{l}\text { Locação } \\
\text { de } \\
\text { veículo }\end{array}$ & $\mathrm{X}$ & & \\
\hline PGE/SP & $\begin{array}{l}\text { Pregão } \\
\text { eletrônico } n^{\circ} \\
3 / 2014\end{array}$ & $23 / 05 / 2014$ & $\begin{array}{l}\text { Locação } \\
\text { de } \\
\text { veículo }\end{array}$ & $\mathrm{X}$ & & \\
\hline $\mathrm{MP} / \mathrm{SP}$ & $\begin{array}{l}\text { Pregão } \\
\text { eletrônico } n^{\circ} \\
8 / 2014\end{array}$ & $08 / 10 / 2014$ & $\begin{array}{l}\text { Aquisição } \\
\text { de } \\
\text { veículo }\end{array}$ & & $\mathrm{X}$ & \\
\hline TCE/SP & $\begin{array}{l}\text { Pregão } \\
\text { presencial no } \\
25 / 2014\end{array}$ & $11 / 11 / 2014$ & $\begin{array}{l}\text { Aquisição } \\
\text { de } \\
\text { veículo }\end{array}$ & & $\mathrm{X}$ & \\
\hline DPE/SP & $\begin{array}{l}\text { Pregão } \\
\text { eletrônico } n^{\circ} \\
100 / 2015\end{array}$ & $14 / 12 / 2015$ & $\begin{array}{l}\text { Locação } \\
\text { de } \\
\text { veículo }\end{array}$ & $\mathrm{X}$ & & \\
\hline DPE/SP & $\begin{array}{l}\text { Pregão } \\
\text { eletrônico no } \\
77 / 2015\end{array}$ & $08 / 10 / 2015$ & $\begin{array}{l}\text { Abasteci } \\
\text { mento de } \\
\text { combustí } \\
\text { veis de } \\
\text { veículos }\end{array}$ & & $\mathrm{X}$ & \\
\hline $\mathrm{TJ} / \mathrm{SP}$ & $\begin{array}{l}\text { Pregão } \\
\text { eletrônico no } \\
193 / 2015\end{array}$ & $29 / 07 / 2015$ & $\begin{array}{l}\text { Abasteci } \\
\text { mento de } \\
\text { combustí } \\
\text { veis de } \\
\text { veículos }\end{array}$ & & & $\mathrm{X}$ \\
\hline PGE/SP & $\begin{array}{l}\text { Pregão } \\
\text { eletrônico } n^{\circ} \\
06 / 20164\end{array}$ & $06 / 06 / 2016$ & $\begin{array}{l}\text { Locação } \\
\text { de } \\
\text { veículo }\end{array}$ & $\mathrm{X}$ & & \\
\hline $\mathrm{MP} / \mathrm{SP}$ & $\begin{array}{l}\text { Pregão } \\
\text { presencial no } \\
10 / 2016\end{array}$ & $06 / 09 / 2016$ & $\begin{array}{l}\text { Locação } \\
\text { de } \\
\text { veículo }\end{array}$ & & & $\mathrm{X}$ \\
\hline TCE/SP & $\begin{array}{l}\text { Pregão } \\
\text { presencial no } \\
21 / 2016\end{array}$ & $26 / 04 / 2016$ & $\begin{array}{l}\text { Abasteci } \\
\text { mento de } \\
\text { combustí } \\
\text { veis de } \\
\text { veículos }\end{array}$ & & $\mathrm{X}$ & \\
\hline $\mathrm{MP} / \mathrm{SP}$ & $\begin{array}{l}\text { Pregão } \\
\text { eletrônico } n^{\circ} \\
04 / 2016\end{array}$ & $18 / 04 / 2016$ & $\begin{array}{l}\text { Abasteci } \\
\text { mento de } \\
\text { combustí } \\
\text { veis de } \\
\text { veículos }\end{array}$ & & $\mathrm{X}$ & \\
\hline $\mathrm{TJ} / \mathrm{SP}$ & $\begin{array}{l}\text { Pregão } \\
\text { eletrônico }{ }^{\circ}\end{array}$ & $10 / 06 / 2016$ & $\begin{array}{l}\text { Abasteci } \\
\text { mento de } \\
\text { combustí }\end{array}$ & & & $\mathrm{X}$ \\
\hline
\end{tabular}

Revista Gestão e Secretariado (GeSec), São Paulo, SP, v. 10, n. 2, mai/ago, 2019, p. 87-111. 


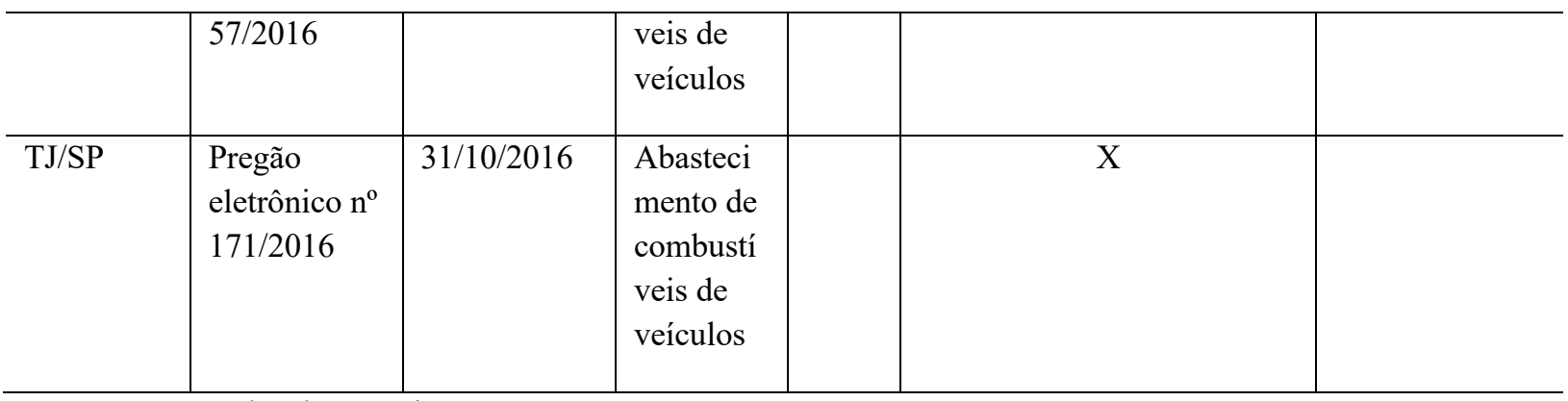

Nota. Fonte: Dados da Pesquisa

A tabela 1 pode ser analisada sob diversos aspectos. Inicialmente se observa que a coleta considerou 4 editais produzidos em 2014, 4 editais produzidos em 2015 e 6 editais produzidos em 2016. Desses 14 editais analisados, 4 (28,5\%) fizeram menção direta ao Decreto Estadual $\mathrm{n}^{\mathrm{o}} 59.038 / 2013$, atendendo totalmente aos critérios de sustentabilidade destacados pela norma. Já 7 (50\%) editais atenderam às determinações da norma, apesar de não citarem o decreto. E apenas $3(21,5 \%)$ não citaram o decreto e não atenderam a requisitos do decreto.

À primeira vista, é grande o percentual de $21,5 \%$ de não atendimento à norma, pois é um critério bastante simples de ser atendido e o Estado de São Paulo é referência no atendimento ao conceito de que o poder público deve liderar o aguçamento pela consciência ambiental, como define Coelho (2014). Então, passamos para uma análise mais apurada desses editais que não atenderam às regras sustentáveis.

Dois deles foram produzidos pelo Tribunal de Justiça de São Paulo (pregões

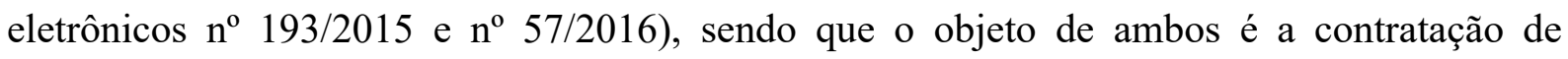
serviços de abastecimento da frota exclusivamente com gasolina, o que vai totalmente de encontro com a previsão legal. No entanto, os outros dois editais analisados deste mesmo órgão (pregões eletrônicos $n^{\circ} 220 / 2015$ e $n^{0}$ 171/2016), notam que seus objetos são para contratação de serviços de abastecimento da frota com etanol e diesel. Portanto, o ente divide sua contratação de abastecimento, e apesar de não citar diretamente o decreto, o Tribunal de Justiça atende os critérios ambientais definidos.

Apenas o edital do Ministério Público (pregão presencial $n^{\circ} 10 / 2016$ ), referente à locação de um veículocom motor à gasolina, não há qualquer justificativa.

Revista Gestão e Secretariado (GeSec), São Paulo, SP, v. 10, n. 2, mai/ago, 2019, p. 87-111. 
A atuação do órgão causa espécie, pois os outros 2 editais analisados (pregão eletrônico no 008/2014 e no 004/2016), sendo um de aquisição de veículo e outro de serviço de abastecimento, atenderam aos critérios ambientais do decreto, embora não fizessem citação direta à norma.

Diante do cenário apurado, é possível concluir que os órgãos estaduais paulistas estão afinados com as determinações legais. Talvez a disponibilização de ferramentas no Sistema $\mathrm{BEC} / \mathrm{SP}$, que é utilizado por todos esses órgãos nas compras eletrônicas, bem como em consultas em geral, seja um fator acelerador de divulgação das regras socioambientais que devem ser aplicadas às licitações e compras públicas.

No entanto, a falta de menção ao decreto em grande parte dos editais, pode ser considerada não muito positiva, pois a partir do momento em que as regras são mais amplamente divulgadas, o impacto nos mercados produtores e fornecedores é muito maior. A citação do decreto diretamente no edital ou no contrato tem um impacto pedagógico e permite maior amplitude de divulgação das regras, assim garante a preservação do direito ao futuro ambientalmente limpo das gerações vindouras (Freitas, 2016).

\section{CONSIDERAÇÕES FINAIS}

Toda a evolução do conceito de sustentabilidade trouxe reflexos na forma de atuação dos órgãos públicos, impulsionou a criação de uma grande quantidade de normas, bem como influenciou os mandamentos constitucionais brasileiros. Diante desse cenário mundial de mudanças, nota-se que os gestores públicos não podem mais realizar aquisições e contratações sem o compromisso com as práticas sustentáveis, sob pena de transgredir mandamentos legais e constitucionais e serem responsabilizados.

As licitações e as contratações públicas, mais do que formas de a Administração Pública contratar ou adquirir serviços e produtos, são consideradas como políticas públicas, tendo em vista que tais ações têm um impacto econômico muito elevado, sendo capazes de incentivar mudanças de comportamento na produção e no mercado.

Revista Gestão e Secretariado (GeSec), São Paulo, SP, v. 10, n. 2, mai/ago, 2019, p. 87-111. 
Durante a análise de algumas contratações realizadas por um determinado grupo de órgãos públicos no Estado de São Paulo, observou-se que a utilização de um sistema de compras integrado, permite maior facilidade de divulgação das mudanças nas práticas das compras e licitações, refletindo inclusive nos critérios socioambientais.

Nos editais selecionados para a pesquisa, esperava-se que todos atendessem os critérios ambientais do decreto destacado para comparação e, na maior parte, fosse citado o decreto, ou ao menos o "Programa Paulista de Biocombustíveis". Os resultados foram um pouco diversos, pois cerca dos $92 \%$ dos editais atendem aos requisitos analisados. Apenas do ponto de vista pedagógico de divulgação da norma que o resultado fica aquém, e pode ser melhorado ao longo do tempo.

A criação de normas e disponibilização de ferramentas com critérios socioambientais são de grande relevância para a mudança de comportamento dentro dos órgãos públicos, tendo em vista o princípio da legalidade que é a força motriz das atuações públicas. Porém, mais que isso, a mudança de cultura dos órgãos é muito mais efetiva quando existe um maior envolvimento dos responsáveis pelo alto escalão, que implantam políticas internas e disponibilizam ferramentas e treinamentos para a efetivação das práticas socioambientais.

Nota-se que a existência de normas é importante, mas a divulgação das informações e insistência com os benefícios de adoção de posturas sustentáveis tem função pedagógica bastante relevante para a efetiva mudança de cultura.

Esta pesquisa poderá ser ampliada através da seleção de outros aspectos socioambientais (ambiental, social, econômica, ética ou jurídico-política) dentro dos editais disponibilizados pelos órgãos públicos paulistas em seus sítios eletrônicos.

\section{REFERÊNCIAS}

Advocacia-Geral da União. Consultoria-Geral da União (2016). Guia Nacional de Licitações Sustentáveis. F. G Carvalho, M. A. S. O. Ferreira \& T.Villac. Brasília: AGU.

Arrowsmith, S.,Treumer, S.,Fejo, J.\& Jiang, L. (2011) Public Procurement Regulation: An Introduction. EU Asia Inter University Network for Teaching and Research in Public Procurement Regulation. Universityof Nottingham, UK.Recuperado 
de: $<$ https://www.nottingham.ac.uk/pprg/documentsarchive/asialinkmaterials/publicprocu rementregulationintroduction.pdf.

Barcessat, L. (2015) Papel do Estado Brasileiro na Ordem Econômica e na Defesa do Meio Ambiente: Necessidade de Opção por Contratações Públicas Sustentáveis. In: M. G. Santos\& T. Villac (Coord.). Licitações e contratações públicas sustentáveis. 2 ed. Belo Horizonte: Fórum.

Bertogna, V. (2015) Princípios Constitucionais Ambientais Aplicáveis às Licitações Sustentáveis. In: M. G. Santos\& T. Villac (Coord.). Licitações e contratações públicas sustentáveis. 2 ed. Belo Horizonte: Fórum.

Bolsa Eletrônica de Compras. (2017) Portal do sistema eletrônico de contratações do Estado de São Paulo. Recuperado de $<$ https://www.bec.fazenda.sp.gov.br/publico/aspx/Home.aspx>.

Coelho, H. A. (2014) Responsabilidade Ambiental na Licitação: Sustentabilidade nas contratações e compras de governo. Rio de Janeiro: Lumen Juris.

Comissão Europeia. (2016) Comprar Ecológico! Manual de Contratos Públicos Ecológicos. 3 ed. Luxemburgo: Serviço das Publicações da União Europeia. Recuperado

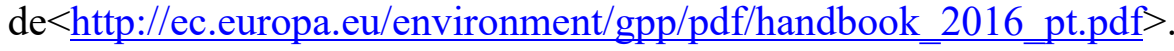

Constituição da República Federativa do Brasilde 1988. Recuperado de $<$ http://www.planalto.gov.br/ccivil_03/constituicao/constituicaocompilado.htm>.

Costa, C. F., Diniz, M. F. S., Cunha, N. R. S. \& Pires, R. R. (2016) O Fator Sustentabilidade nas Licitações e Contratações Públicas. Revista REUNA, v.21, n.4, p.37-56. Belo Horizonte: REUNA. Recuperado de

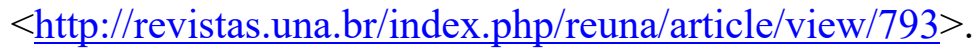

Decreto Estadual $n^{\circ}$ 59.038, de 03 de abril de 2013. Institui o Programa Paulista de Biocombustíveis e dá providências correlatas. Recuperado de. $<$ https://www.al.sp.gov.br/repositorio/legislacao/decreto/2013/decreto-5903803.04.2013.html>.

Decreto Estadual no 42.836, 02 de fevereiro de 1998. Dispõe sobre a aquisição e locação de veículos pelas Unidades Frotistas pertencentes à Administração Direta e Indireta do Estado. Recuperado de https://www.al.sp.gov.br/repositorio/legislacao/decreto/1998/decreto-4283602.02.1998.html>.

Decreto Estadual $n^{\circ} 50.170$, de 04 de novembro de 2005. Institui o Selo Socioambiental no âmbito da Administração Pública Estadual. Recuperado de https://www.al.sp.gov.br/repositorio/legislacao/decreto/2005/decreto-5017004.11.2005.html>.

Decreto Estadual $n^{0}$ 53.336, de 20 de agosto de 2008. Institui o Programa Estadual de Contratações Públicas Sustentáveis e dá providências correlatas. Recuperado de $<$ https://www.al.sp.gov.br/repositorio/legislacao/decreto/2008/decreto-5333620.08.2008.html>. 
Freitas, J. (2016) Sustentabilidade - Direito ao Futuro. 3 ed. Belo Horizonte: Fórum.

Freitas, T. P. (2014) Sustentabilidade e as Contratações Públicas. Rio de Janeiro: Lumen Juris.

Gil, A. C. (2010) Como elaborar projetos de pesquisa. 5 ed. São Paulo: Atlas.

ICLEI. (2015) Manual Procura+ Um Guia para Implementação de Compras Públicas Sustentáveis. 3 ed. São Paulo, Recuperado de http://www.tjdft.jus.br/acessorapido/acoes/viver-direito/manuais/manual-compras-sustentaveis-iclei.

ICLEI América do Sul. (2017) Recuperado dehttp://sams.iclei.org/quem-somos/o-iclei.html.

Lei Federal $n^{0}$ 6.938, de 31 de agosto de 1981.Dispõe sobre a Política Nacional do Meio Ambiente, seus fins e mecanismos de formulação e aplicação, e dá outras providências. Recuperado de< http://www.planalto.gov.br/ccivil_03/leis/L6938.htm>.

Lei Federal $\mathrm{n}^{\mathrm{o}}$ 8.666, de 21 de junho de 1993. Regulamenta o art. 37, inciso XXI, da Constituição Federal, institui normas para licitações e contratos da Administração Pública e dá outras providências. Recuperado de < http://www.planalto.gov.br/ccivil_03/leis/L8666cons.htm>.

Lei Federal $\mathrm{n}^{\mathrm{o}}$ 12.462, de 04 de agosto de 2011. Institui o Regime Diferenciado de Contratações Públicas - RDC; altera a Lei ${ }^{\circ}$ 10.683, de 28 de maio de 2003, que dispõe sobre a organização da Presidência da República e dos Ministérios, a legislação da Agência Nacional de Aviação Civil (Anac) e a legislação da Empresa Brasileira de Infraestrutura Aeroportuária (Infraero); cria a Secretaria de Aviação Civil, cargos de Ministro de Estado, cargos em comissão e cargos de Controlador de Tráfego Aéreo; autoriza a contratação de controladores de tráfego aéreo temporários; altera as Leis nos 11.182 , de 27 de setembro de 2005, 5.862, de 12 de dezembro de 1972, 8.399, de 7 de janeiro de 1992, 11.526, de 4 de outubro de 2007, 11.458, de 19 de março de 2007, e 12.350, de 20 de dezembro de 2010, e a Medida Provisória no 2.185-35, de 24 de agosto de 2001; e revoga dispositivos da Lei no 9.649, de 27 de maio de 1998. Recuperado de< http://www.planalto.gov.br/ccivil_03/_ato2011-2014/2011/lei/112462.htm>.

Martins, G. A.,Theóphilo, C. R. (2009) Metodologia da investigação científica para ciências sociais aplicadas. 2 ed. São Paulo: Atlas.

Meneguzzi, R. M. (2015). Conceito de Licitação Sustentável. In: M. G. Santos \& T.Villac. (Coord.). Licitações e contratações públicas sustentáveis. 2 ed. Belo Horizonte: Fórum.

Ministério do Meio Ambiente (2017) Agenda ambiental na administração pública - A3P. Recuperado de $<$ https://http://www.mma.gov.br/responsabilidade-socioambiental/a3p>.

Ministério do Meio Ambiente (2017) Processo de Marrakesh. Recuperado de $<\underline{\text { http://www.mma.gov.br/responsabilidade-socioambiental/producao-e-consumo- }}$ sustentavel/plano-nacional/processo-de-marrakesh $>$.

Ministério Público do Estadode São Paulo. Editais.Recuperado de $<$ http://www.mpsp.mp.br/portal/page/portal/licitacoes/pesquisar_licitacoes $>$. 
Moreira, D. A.(2011) Licitação Sustentável: inserção da variação ambiental no sistema de compras e contratações públicas. In: A. H. Benjamin\&G. J. P. Figueiredo. (Coord.). Direito Ambiental e as Funções Essenciais à Justiça: o papel da Advocacia de Estado e da Defensoria Pública na Proteção do Meio Ambiente. São Paulo: Revista dos Tribunais.

Moreira, R. M. C.(2017) Direito Administrativo e Sustentabilidade - O novo controle judicial da Administração Pública. Belo Horizonte: Fórum.

Procuradoria Geral doestado de São Paulo. Editais.Recuperado de. $<$ http://www.pge.sp.gov.br/editais/licitacoes/index.aspx $>$.

Sampieri, R. H., Collado, C. F.\& Lucio, M. P. B. (2013) Metodologia de Pesquisa. 5 ed. Porto Alegre: McGraw-Hill.

Sarlet, I. W. \&Fensterseifer, T. (2013) Direito Constitucional Ambiental - Constituição, Direitos Fundamentais e Proteção do Ambiente. 3 ed. São Paulo: Revista dos Tribunais.

Silva, R. C. \&,Barki, T. V. P. (2012) Compras Públicas Compartilhadas: A Prática das Licitações Sustentáveis. Revista do Serviço Público. Vol. 63. Número 2. Brasília: ENAP, Recuperado de. $<$ https://revista.enap.gov.br/index.php/RSP/article/view/93 $>$.

Torres, R. L. (2012) Licitações sustentáveis: sua importância e seu amparo constitucional e legal. Interesse Público - IP, Belo Horizonte, ano 14, n. 71, jan./fev. 2012. Recuperado de. $<$ revista.tcu.gov.br/ojs/index.php/RTCU/article/download/199/192>.

Tribunal de Contas da União. Acórdão $\mathrm{n}^{\mathrm{o}}$ 1751/2011 - Plenário - Processo $\mathrm{n}^{\mathrm{o}}$ TC 017.517/2010-9. Relator Ministro-Substituto André Luís de Carvalho. Data da Sessão: 29/06/2011.Recuperado.<http://www.tcu.gov.br/Consultas/Juris/Docs/CONSES/TCU_A TA_0_N_2011_25.pdf $>$.

Tribunal de Contas da União. Acórdão $\mathrm{n}^{\mathrm{o}}$ 1056/2017 - Plenário - Processo $\mathrm{n}^{\mathrm{o}} \mathrm{TC}$ 006.615/2016-3. Relator Ministro-Substituto André Luís de Carvalho. Data da Sessão: 24/5/2017. Recuperado de.

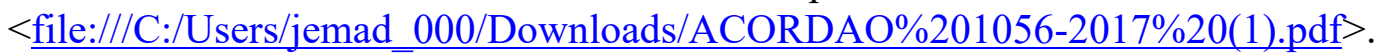

Tribunal de Contas do Estado de São Paulo. Editais.Recuperado de. $<$ http://www4.tce.sp.gov.br/licitacao/licitacoes>. Acesso em: 14 nov. 2017.

Tribunal de Justiça do Estado de São Paulo. TJ Sustentável. São Paulo: (2017). Recuperado de. $<$ http://www.tjsp.jus.br/tjsustentavel/Home/Apresentacao $>$.

Tribunal de Justiça de São Paulo. Editais. São Paulo: (2017). Recuperadode. $<$ http://www.tjsp.jus.br/portalscl/consultarLicitacaoEdital.do?onLoad=fals e>.

WWF Brasil. (2017) Pegada Ecológica Global. Recuperado de. $<$ http://www.wwf.org.br/natureza_brasileira/especiais/pegada_ecologica/pegada_ecolo gica global/>.

Submetido em: 27.09.2018

Aceito em: 12.04.2019

Revista Gestão e Secretariado (GeSec), São Paulo, SP, v. 10, n. 2, mai/ago, 2019, p. 87-111. 